\title{
Range effects using instrumental choice procedures
}

\author{
JOHN M. HINSON \\ Washington State University, Pullman Washington \\ and \\ LINDA R. TENNISON \\ Longwood College, Farmville, Virginia
}

\begin{abstract}
Pigeons were trained to discriminate visual flicker-rate stimuli using two types of instrumental choice procedures. One experiment used a free-operant concurrent schedule with multiple schedule components. Two additional experiments used a two-alternative, discrete-trial procedure. In all experiments, the range of training stimuli was manipulated across conditions. Results from all three experiments showed typical range effects on discrimination performance. That is, performance declined with increases in the overall range of variation of training stimuli. These range effects occurred with either continuous response rate measures or discrete choice measures. Moreover, range effects appeared with relatively high or low levels of overall discrimination accuracy and with either symmetrical or asymmetrical extensions of stimulus range. The results of these experiments suggest that increasing stimulus range influences both perceptual sensitivity and bias to response alternatives.
\end{abstract}

The ability to distinguish among stimuli in psychophysical tasks depends not only on the physical differences among the stimuli but also on the context in which judgments are made. Stimulus range effects are a robust example of such context dependency (e.g., Algom \& Marks, 1990; Durlach \& Braida, 1969; Gravetter \& Lockhead, 1973; Nosofsky, 1983; Pollack, 1952). Range effects are identified as a decrease in the accuracy of psychophysical judgment resulting from an increase in the overall range of stimuli being judged. This effect of stimulus range appears in a variety of judgment tasks (e.g., Parducci, 1974), and it is reflected by several dependent measures, such as error rates in absolute identification, variability increases in magnitude estimation, and changes in slope of psychometric functions (e.g., Frederiksen, 1975; Lockhead \& King, 1983; Parker \& Schneider, 1994). The production of range effects does not require complex tasks with large numbers of judgment categories. In fact, range effects are found in the simplest possible settings with a minimum number of stimuli and response categories (e.g., Gravetter \& Lockhead, 1973).

Consistent with the findings in the human psychophysical literature, prior studies have reported range effects with pigeons during visual discrimination tasks (Chase, 1983; Hinson \& Lockhead, 1986; Tennison \& Hinson, 1993). As one example (Hinson \& Lockhead, 1986), pigeons were trained to discriminate between $\mathrm{S}+$ and $\mathrm{S}-$, signaled by visual flicker rates. The task was a successive

Correspondence should be addressed to J. M. Hinson, Department of Psychology, Washington State University, Box 644820, Pullman, WA 99164-4820 (e-mail: hinson@mail.wsu.edu). discrimination procedure in which two $\mathrm{S}+$ and two $\mathrm{S}-$ stimuli were presented in a multiple schedule. The $\mathrm{S}+$ and $\mathrm{S}-$ stimuli most similar (i.e., closest in flicker rate) appeared in all conditions. The other two stimuli varied across conditions so that there was relatively small variation in the $\mathrm{S}+$ and $\mathrm{S}-$ stimuli, large variation in the $\mathrm{S}+$ stimuli only, large variation in the S - stimuli only, or large variation in both the $S+$ and the $S-$ stimuli. The general result was that discrimination between $\mathrm{S}+$ and $\mathrm{S}-$ was best with a small stimulus range and worst with the largest stimulus range.

The occurrence of range effects during discrimination learning by animals has important implications for models of conditioning. For example, traditional theories of stimulus control, such as the "strength" models (Balsam, 1988) of Spence (1937) and D. S. Blough (1975) and the "information processing" models based on signal detection theory (e.g., D. S. Blough, 1967; Boneau \& Cole, 1967; Heinemann, Avin, Sullivan, \& Chase, 1969), rely primarily on the physical difference between S+ and Sas an explanation for discrimination performance. The appearance of range effects indicates that contextual factors interact with physical stimulus difference to determine discrimination performance. Traditional conditioning theories do not predict and cannot easily explain range effects (Hinson \& Lockhead, 1986; Tennison \& Hinson, 1993).

The human psychophysical literature provides guidance on the interpretation of range effects. Many theorists have addressed range effects within the framework of signal detection theory or its variants (e.g., Gravetter \& Lockhead, 1973; Luce \& Nosofsky, 1984). The basic detection model does not predict range effects any more 
readily than the previously mentioned conditioning models do, because the detection model also presumes that discrimination performance is fundamentally determined by the overlap between theoretical sensory processes along a physical continuum (e.g., Boneau \& Cole, 1967; Green \& Swets, 1966; McNicol, 1972). Neverthe!ess, the detection approach is flexible, and it can be modified to accommodate range effects. The available models of range effects can be classified by the theoretical emphasis they place on either sensory or response factors (see Luce \& Nosofsky, 1984). By this classification, sensory factors include changes in the internal representation of stimuli that ultimately place limits on perceptual sensitivity. Response factors include response scales or criteria by which stimuli are judged. For convenience, we will speak of perceptual sensitivity when referring to changes due to sensory factors, and we will speak of response bias when referring to changes produced by response factors.

An example of a model that places emphasis on sensory factors is the attention band theory (Luce \& Green, 1978; Luce, Green, \& Weber, 1976). This theory proposes that increases in range indirectly affect sensory variability by presenting a stimulus continuum that is too large to be encompassed by a limited-capacity attentional band. Stimulus representations falling within the attentional band are less variable than those outside the band. To the extent that the stimulus range is large, the probability that a given representation falls within the band is reduced, and thereby discrimination performance declines. Further assumptions posit that the band tends to be located at the extremes of the sensory continuum and tends to track successive stimulus presentations.

In contrast, other models argue that sensory factors are not changed by stimulus context. Instead, declines in performance can be attributed to changes in response factors. For example, the range model (Braida \& Durlach, 1972; Durlach \& Braida, 1969) proposes that observers compare the current stimulus with the memory of the stimulus context. Variability in the response scale that determines which response is made is presumed to increase directly with increases in stimulus range. A related model, the criterial range model developed by Gravetter and Lockhead (1973), posits that the variability of the response criteria increases when stimulus range is increased. In both the range model and the criterial range model, increases in the variability of response factors lead to an apparent decline in discrimination accuracy, even though the stimulus representation has not changed (see also Heinemann et al., 1969, and Macmillan \& Creelman, 1991).

The two types of models described above have some empirical support. At the same time, comparisons of these models have produced ambiguous results, in that the same data may often be accounted for by either type of theory (Luce \& Nosofsky, 1984). In addition, some studies indicate that increases in stimulus range may influence both sensory factors and response factors (e.g., No- sofsky, 1983), suggesting that both types of models may be partially correct.

Our prior studies of range effects with pigeons (Hinson \& Lockhead, 1986; Tennison \& Hinson, 1993) were designed to reduce some of the complications attendant to human judgment. Both sets of studies employed response rate as the dependent measure of discrimination, and both used successive discrimination procedures. Results from these studies generally supported the notion that response factors, rather than sensory factors, are responsible for range effects in animals.

In the first study (Hinson \& Lockhead, 1986), the form of response rate differences indicated that response criterion changes were the most plausible explanation for the observed range effect. For instance, as either $\mathrm{S}-$ or $\mathrm{S}+$ stimulus range increased, overall discrimination performance declined. However, response rates during unchanged $\mathrm{S}$ - and $\mathrm{S}+$ stimuli did not show simple convergence. If discriminability had decreased with increases in stimulus range, we would normally expect $S+$ response rate to decline and $\mathrm{S}$ - rate to increase toward an intermediate value. Instead, absolute response rate during $S-$ and $\mathrm{S}+$ stimuli changed in various ways, whereas relative performance always declined during the increased stimulus range conditions.

In the second study (Tennison \& Hinson, 1993), successive discrimination procedures were used, and stimulus control with either transient or maintained generalization gradients was assessed. Increased stimulus range produced an overall flattening of stimulus control gradients. In transient generalization testing (e.g., Hanson, 1959) and in maintained generalization testing (e.g., P. M. Blough, 1980 ), decreasing the discriminability of $S-$ and $S+$ training stimuli typically steepens the stimulus control gradient. In fact, we found that the flattening of gradients produced by increased stimulus range was the opposite of the steepening found when we made $\mathrm{S}-$ and $\mathrm{S}+$ stimuli more difficult to discriminate (see Tennison \& Hinson, 1993). We concluded that range effects in these experiments were probably due to response factors that influenced the criterion to respond or not respond.

In the present experiments, we attempted to extend and improve our previous work. To begin, with a single response option, as in the prior successive discrimination tasks we have examined, responding during periods of nonreinforcement may be relatively high. As a result, $\mathrm{S}$ - responding would reflect not only discriminability between $\mathrm{S}-$ and $\mathrm{S}+$ stimuli but also the asymmetry of payoffs for responding versus not responding (e.g., Hinson \& Higa, 1989). If responding is relatively effortless, we might expect a bias toward responding in successive discrimination procedures that could obscure our theoretical interpretation of range effects.

Other factors can also complicate our interpretation of results with a response rate measure. For example, in successive discrimination training, behavioral contrast is often produced (e.g., Williams, 1983). Among other variables, behavioral contrast is influenced by the degree to which a 
given stimulus is a good predictor of reinforcement availability. If we increase stimulus range by making one $\mathrm{S}+$ very different from the other stimuli, that $\mathrm{S}+$ stimulus may become a relatively better predictor of reinforcement. As a result, negative behavioral contrast may occur in the other stimuli. In an analogous fashion, increasing stimulus range by making an $\mathrm{S}-$ stimulus very different from other stimuli may lead to positive behavioral contrast in those other stimuli. Such behavioral contrast effects could easily confound a discrimination measure based on response rate.

To control for these potential problems with response rate, we used choice procedures for discrimination training in the present experiments. The use of a two-key concurrent schedule in Experiment 1 helped to eliminate some of the problems with a single response rate measure. In Experiment 1, reinforcement was always available for responding because a valid predictor was always present. The relative value of responding versus not responding was thereby equalized across stimuli and conditions. In Experiment 2, a discrete-trial, two-alternative choice procedure was used. This procedure allowed for comparison between discrete response and continuous response rate measures while maintaining the basic element of choice. Furthermore, Experiment 2 provided a more direct link between operant discrimination measures and detection theory measures of performance. In Experiment 3, one of the findings of Experiment 2 was explored, in which symmetrical and asymmetrical shifts in range were compared. Results from all experiments provided a broader empirical base from which to evaluate potential theoretical explanations of range effects in instrumental conditioning.

\section{EXPERIMENT 1}

Experiment 1 provided an initial investigation of range effects in a choice procedure. Visual stimuli that varied in flicker rate signaled whether responses to the left or right response key would be reinforced. Response rates to the two keys during each stimulus provided a measure of discrimination performance. The overall range of the stimulus set and the separation between bordering $\mathrm{S}+$ and $\mathrm{S}-$ stimuli along the continuum were manipulated in different conditions.

\section{Method}

Subjects. Four homing pigeons with varied training histories served as subjects. The birds were maintained at $80 \%$ of their freefeeding weights and were housed in a local vivarium with a $12: 12$-h light:dark cycle.

Apparatus. The experiments were carried out in a Campden Instruments, three-key operant conditioning chamber. The internal dimensions of the chamber were $35 \times 35 \times 33 \mathrm{~cm}$. The two side translucent pecking keys were $2.72 \mathrm{~cm}$ in diameter and were located $27.5 \mathrm{~cm}$ above the floor and $6 \mathrm{~cm}$ from either side of the chamber. The center key, which was not used, was covered with black tape. A 6-W houselight provided diffuse illumination throughout the chamber during experimental sessions. A $5 \times 6 \mathrm{~cm}$ aperture, located in the middle of the front panel $13.5 \mathrm{~cm}$ from the floor, provided access to the food magazine. Mixed grain presented for $3 \mathrm{sec}$ was used as a reinforcer. The experimental chamber was part of a larger sound-proofing box, which contained a fan for ventilation and for masking of extraneous noise. Experimental events and data collection were controlled by a dedicated microcomputer.

Procedure. The pigeons were trained on a modified concurrent multiple variable-interval (VI) extinction schedule. Components were signaled by visual stimuli that differed in flicker rate. The stimuli were produced by a standard light-emitting diode (LED), with a peak emission wavelength of $580 \mathrm{~nm}$. To the experimenters, the LED appeared to produce a good spectral yellow hue. An LED was located $2 \mathrm{~cm}$ behind each of the two translucent pecking keys. The luminance of the steady LED was approximately $38 \mathrm{~cd} / \mathrm{m}^{2}$; duty cycle of flicker was equal on and off. Selection of appropriate flicker rates for this study was based on our earlier findings (Hinson \& Lockhead, 1986; Tennison \& Hinson, 1993).

A daily session consisted of 120 component presentations, each lasting $30 \mathrm{sec}$. Both side keys presented the same flicker-rate stimulus, selected at random from the four possible values in each experimental condition. The flicker-rate stimulus signaled whether reinforcement was available for either Key 1 (left) or Key 2 (right) responses. In each experimental condition, the flicker-rate stimulus presented on a given trial was selected from a set of four values. Responses to Key 1 during the two lowest flicker rates, Stimuli 1 and 2, were reinforced according to a VI $30-\mathrm{sec}$ schedule, whereas responses to Key 2 during Stimuli 1 and 2 appeared in extinction. Responses to Key 2 during the two highest flicker-rate stimuli, Stimuli 3 and 4, were reinforced by a VI 30-sec schedule, whereas responses to Key 1 during Stimuli 3 and 4 were extinguished.

Figure 1 shows a schematic representation of the four stimulus values that were presented in each of the experimental conditions. The stimuli are placed on a logarithmic scale to roughly equate the ratio of change for end stimuli on either side of the continuum. Two aspects of the stimulus set were manipulated. First, the separation between stimuli at the border between $\mathrm{S}-$ and $\mathrm{S}+$ response classes was either $1 \mathrm{~Hz}$ (more difficult) or $3 \mathrm{~Hz}$ (less difficult). Second, for each of the two border separations, stimuli at the end points of the stimulus set were selected that provided either a relatively narrow range or a relatively wide range. Each bird served in all four of the experimental conditions, presented in different orders. The duration of training for each condition was 14 sessions.

\section{Results and Discussion}

Figure 2 displays mean response rates, averaged across all 4 birds, for each of the four experimental conditions.

\section{RESPONSE 1 RESPONSE 2}

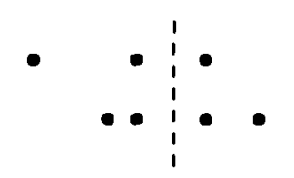

[BORDER $3 \mathrm{HZ}$ ]

- WIDE RANGE

NARROW RANGE

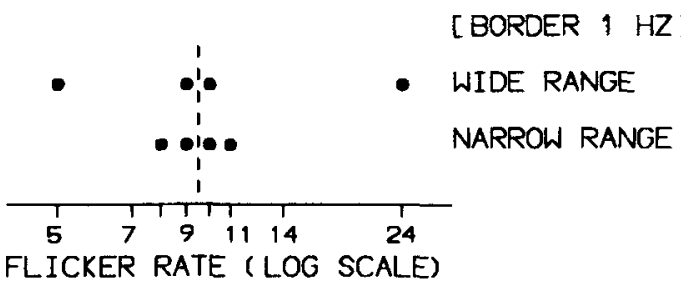

Figure 1. Schematic representation of training stimuli for $E x-$ periments 1 and 2. 

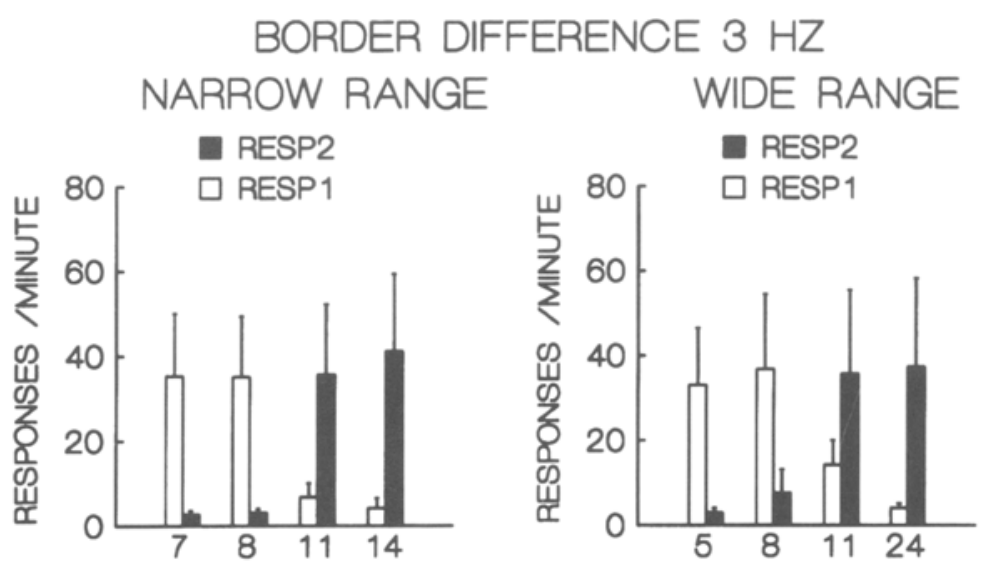

FLICKER RATE

FLICKER RATE

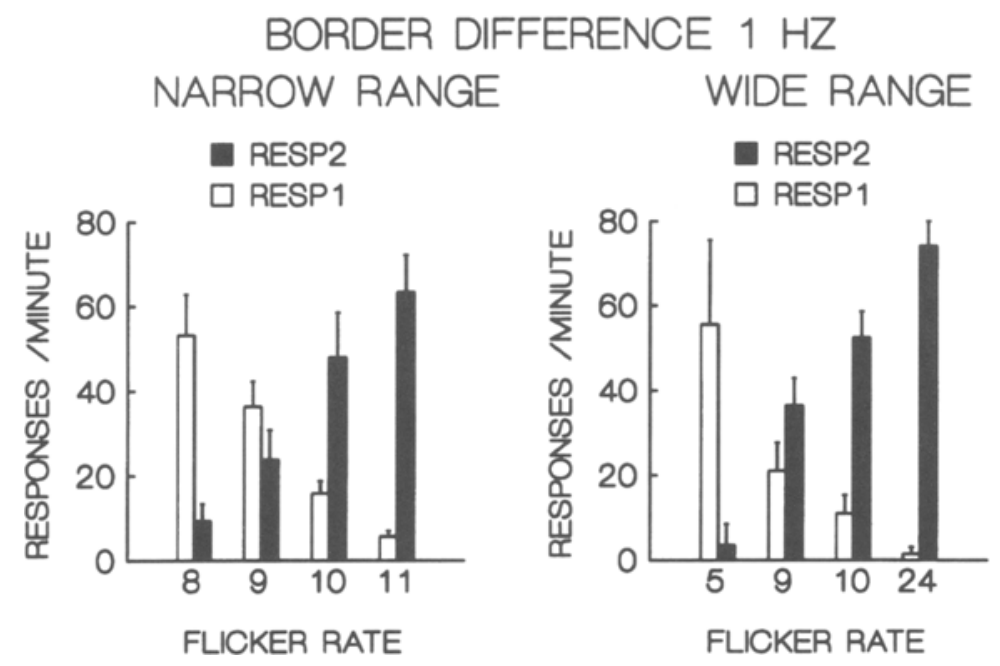

Figure 2. Mean response rate averaged across birds for the last seven sessions of each condition of Experiment 1 . Error bars are the standard errors of the mean.

This figure shows that the birds, as a group, had no trouble making the discrimination between $\mathrm{S}-$ and $\mathrm{S}+$. In all cases, response rate for Key 1 was highest during Stimuli 1 and 2, whereas response rate for Key 2 was highest during Stimuli 3 and 4 . There was an appropriate crossover in the response rate profile, such that rate to Key 1 declined from Stimulus 1 to Stimulus 4, whereas rate to Key 2 showed a corresponding increase. Also, there was less total responding to the incorrect key with the $3-\mathrm{Hz}$ border than with the $\mathrm{1}-\mathrm{Hz}$ border, indicating that the 3$\mathrm{Hz}$ border was in fact an easier discrimination task.

To examine the impact of stimulus range, we next compare the wide and narrow stimulus range conditions. Figure 3 provides plots of relative response rate to Key 1 for individual birds during the $1-\mathrm{Hz}$ border conditions. These plots show the proportion of responding made to Key 1 compared with total responding to both keys (Key 1 plus Key 2), as a function of stimulus. Responding during the narrow range condition is represented by open circles; responding during the wide range condition is represented by filled circles. The slope of the connecting line between Stimulus 2 and Stimulus 3 was steeper in the narrow range condition for all birds. This means that relative discrimination between $\mathrm{S}+$ and $\mathrm{S}-$ stimuli was better with a narrow stimulus range.

Figure 4 provides results for training with the $3-\mathrm{Hz}$ border. Again, for all 4 birds, the slope of the connecting line was steeper in the narrow range condition, indicating that discrimination performance is relatively better. Thus, with both the easier and more difficult border separations, discrimination performance declined with increases in overall stimulus range.

These results can be confirmed by comparing difference scores for responding to Stimuli 2 and 3 across range conditions. For each bird, we computed the difference in relative responding to Stimuli 2 and 3 during the narrow and wide range conditions and then assessed stat1stical significance with a paired-sample $t$ test, using a two-tail criterion of $p<.05$. For the $1-\mathrm{Hz}$ border separation, the difference in relative response rate was significantly greater in the narrow condition $[t(3)=6.209]$, with a mean difference of 17 responses, minute. Difference in 

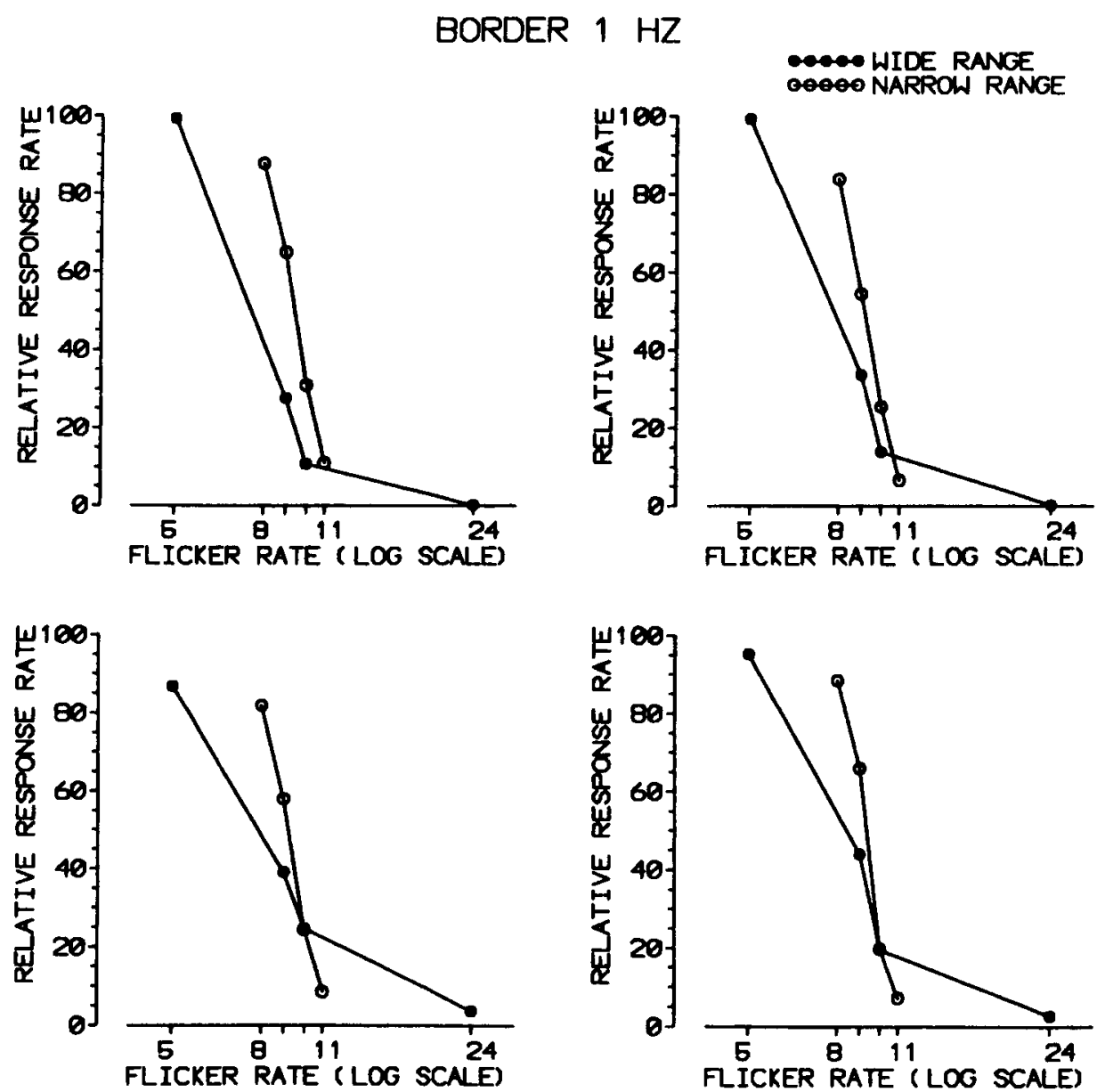

Figure 3. Mean relative response rate for individual subjects during narrow (open circles) and wide (filled circles) range conditions for training with a 1-Hz border in Experiment 1. The ordinate represents percentage of total response rate made to Key 1 . The abscissa represents the logarithm of flicker frequency.

relative response rate was also significantly greater in the narrow condition with a $3-\mathrm{Hz}$ border separation $[t(3)=$ 18.994], yielding a mean difference of 23 responses/ minute.

Although Figures 3 and 4 both show range effects, there is an apparent difference in the pattern of results for the $\mathrm{l}-\mathrm{Hz}$ and $3-\mathrm{Hz}$ border conditions. First consider the results in Figure 3. Relative response rate to Key 1 increased during Stimulus 2 (correct responses). At the same time, relative rate during Stimulus 3 (incorrect responses) either remained the same or showed a smaller increase than the rate for Stimulus 2. That is, even when Key 1 responses increased for both stimuli, relative discrimination between Stimuli 2 and 3 was better with a narrow stimulus range.

Now consider the results from the narrow range condition in Figure 4. In this case, Key 1 responses to Stimulus 2 (correct responses) increased, whereas responses to Stimulus 3 (incorrect responses) decreased. Relative discrimination between Stimulus 2 and Stimulus 3 was again better in the narrow range condition. But the dif- ference between the functions in Figure 4 was due to a divergence of correct and incorrect response rates in the narrow range condition.

If we treat the functions in Figures 3 and 4 as an approximation to a sigmoidal psychometric function, then two distinct changes are possible with increases in stimulus range. First, if discriminability declines with increases in stimulus range, the clearest indication of this would be a convergence of response rates for $\mathrm{S}-$ and $\mathrm{S}+$. Thus, the slope of the function would decrease as response rates to $\mathrm{S}-$ and $\mathrm{S}+$ approached equality. Second, if response preference changes with stimulus range, response rate for the preferred alternative would increase for both $\mathrm{S}-$ and $\mathrm{S}+$. In this case, the apparent change in slope of the function would actually be an indirect result of the changing preference for one alternative and a measurement ceiling on the magnitude of this change.

Experiment 1 seems to have produced both possibilities outlined above. In the $1-\mathrm{Hz}$ border condition, increased stimulus range appears to have produced a change in response factors - namely, an increased bias for re- 

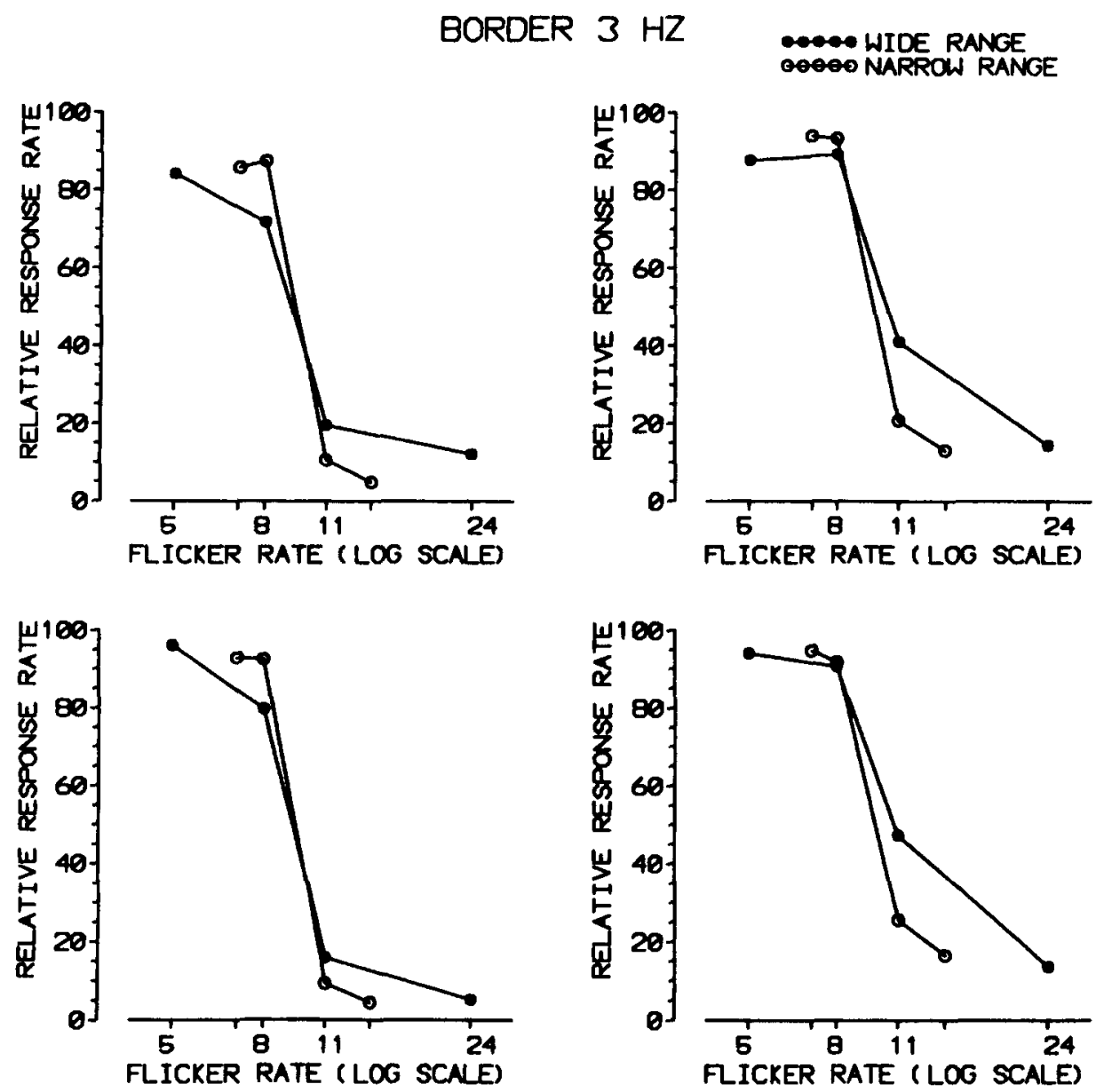

Figure 4. Mean relative response rate for individual subjects during narrow (open circles) and wide (filled circles) range conditions for training with a 3-Hz border in Experiment 1 . The ordinate represents percentage of total response rate made to Key 1 . The abscissa represents the logarithm of flicker frequency.

sponding to Key 2 . On the other hand, the results for the $3-\mathrm{Hz}$ border condition reflect a convergence of response rates during $\mathrm{S}-$ and $\mathrm{S}+$ when stimulus range was increased. This convergence is more consistent with the view that sensory factors, such as a decline in perceptual sensitivity, are changing when range is increased. Thus, in Experiment 1, there is evidence of changes in both sensory factors and response factors as a function of stimulus range. This outcome is inconsistent with our earlier suggestion that range effects in instrumental conditioning studies are due solely to response factors rather than changes in perceptual sensitivity (e.g., Tennison \& Hinson, 1993). Instead, the present findings are more consistent with reports in the human psychophysical literature indicating that both sensory and response factors contribute to range effects (e.g., Nosofsky, 1983).

We can also examine whether there are any systematic changes in responding that occur locally in time. A number of previous studies have shown that responding within experimental sessions often changes in striking ways (e.g., McSweeney \& Hinson, 1992). One recent interpretation is that local changes in responding represent the interaction of habituation and sensitization to the reinforcer (see McSweeney, Hinson, \& Cannon, 1996). In the present experiment, it could be that differences in overall responding during the narrow and wide border conditions were a result of different degrees of habituation that occur with relatively difficult or relatively easy discriminations.

Figures 5 and 6 provide plots of local responding within session averaged across all 4 birds. These plots are running means of absolute response rate to Key 1 and Key 2 , based on an average of 30 consecutive stimulus components. The first point averages components $1-30$, the next point averages components $2-31$, and so on. These figures provide an indication of local variability in response rates and should show any systematic changes in responding over time. As Figure 5 reveals, there were no dramatic changes in response rate over time for the $1-\mathrm{Hz}$ border conditions, although rate did sometimes decline slowly or increase slowly. Figure 6 shows comparable plots for the $3-\mathrm{Hz}$ border conditions. In this figure, it can be seen that there was a slight tendency for correct responding to 


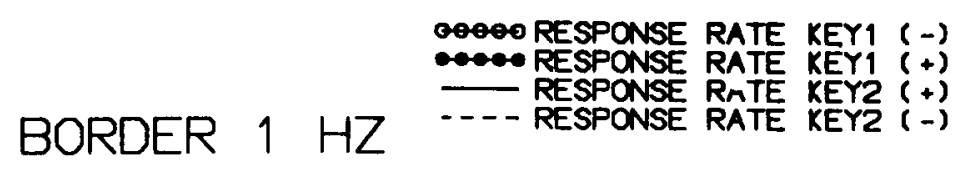

NARROW RANGE

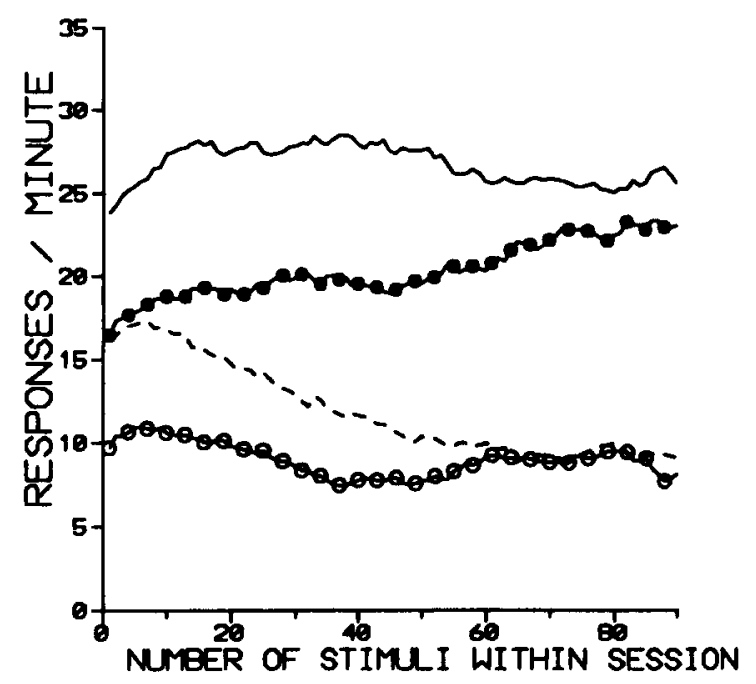

WIDE RANGE

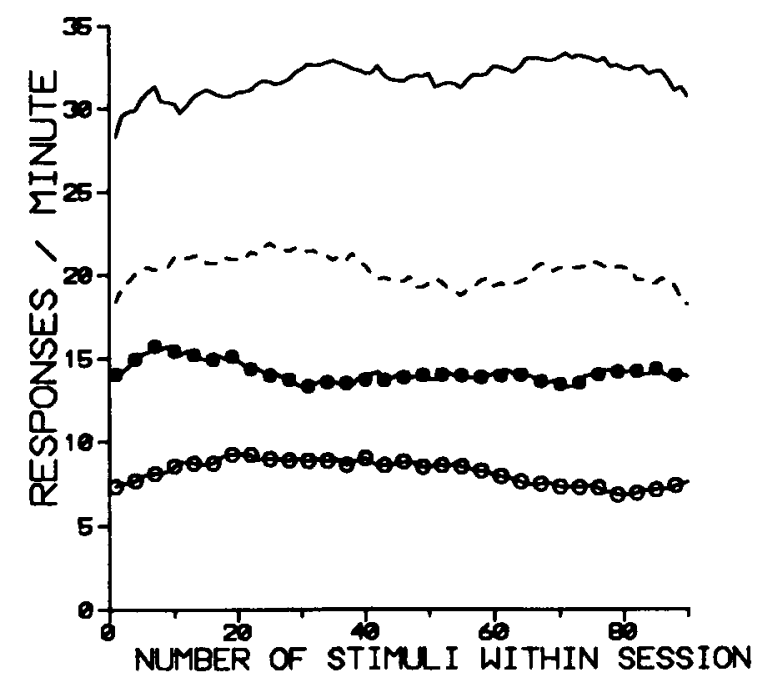

Figure 5. Running mean of response rate over 30 consecutive stimulus components, averaged over all subjects for the last seven sessions of training with a 1-Hz border in Experiment 1. Stimulus range conditions appear in the left panel (narrow) and right panel (wide).

increase for both keys during the early part of the session. Otherwise, there were no dramatic or systematic changes in local responding during the session.

\section{EXPERIMENT 2}

In Experiment 1, we found that range effects occur with choice procedures that minimize the problems inherent in a single response rate measure of discrimination. Unlike the results from our earlier study (e.g., Tennison \& Hinson, 1993), the range effects in Experiment 1 could not be attributed exclusively to response factors, such as a change in response bias. Instead, there was evidence of the influence of both stimulus factors and response factors in the production of range effects. Thus, a single response rate measure may not be the best way to examine the multiple factors that contribute to range effects.

Even within traditional operant models of stimulus control, response rate data can be difficult to interpret (D. S. Blough, 1965, 1983; Hinson \& Higa, 1989). As an alternative to response rate measures, researchers adopting the signal detection model usually employ discretetrial tasks. Discrete-trial choice results are more easily analyzed by detection theory and are presumably less contaminated by extraneous variables than are rate measures (Heinemann et al., 1969; Heinemann \& Chase, 1975).

Experiment 2 was designed to examine range effects in a discrete-trial, two-alternative matching task that would eliminate response rate from the procedure. The training stimuli and stimulus conditions were identical to those used in Experiment 1. But the procedure was somewhat more complicated than the usual discrete-trial task, in that the birds were required to match each flicker stimulus with an arbitrary color key in order to obtain reinforcement. A matching procedure was used to balance out any effect of key position preference in the reinforcement contingency.

\section{Method}

Subjects. Four homing pigeons with varied training histories served as subjects. The birds were maintained at $80 \%$ of their freefeeding weights and were housed in a local vivarium with a 12:12-h light:dark cycle.

Apparatus. The apparatus was identical in configuration to that described in Experiment 1, with the following two exceptions. First, the center key was functional and had a single LED mounted behind it. Second, the two side keys could be illuminated from behind with either a red or a green incandescent lamp.

Procedure. The two-alternative matching task was implemented as follows. At the outset of each trial, a flicker-rate stimulus, drawn at random from the set for the appropriate condition, appeared on the center key. The first response on the center key after $5 \mathrm{sec}$ produced the lighted side keys. The left key was randomly assigned either the red or the green light on each trial, with the right key receiving the alternate color assignment. A single response to either side key ended the trial.

In each condition, responses to the green color key during the two lowest flıcker rates were reinforced with 3-sec access to grain, whereas responses to the red color key produced a 3-sec blackout. 

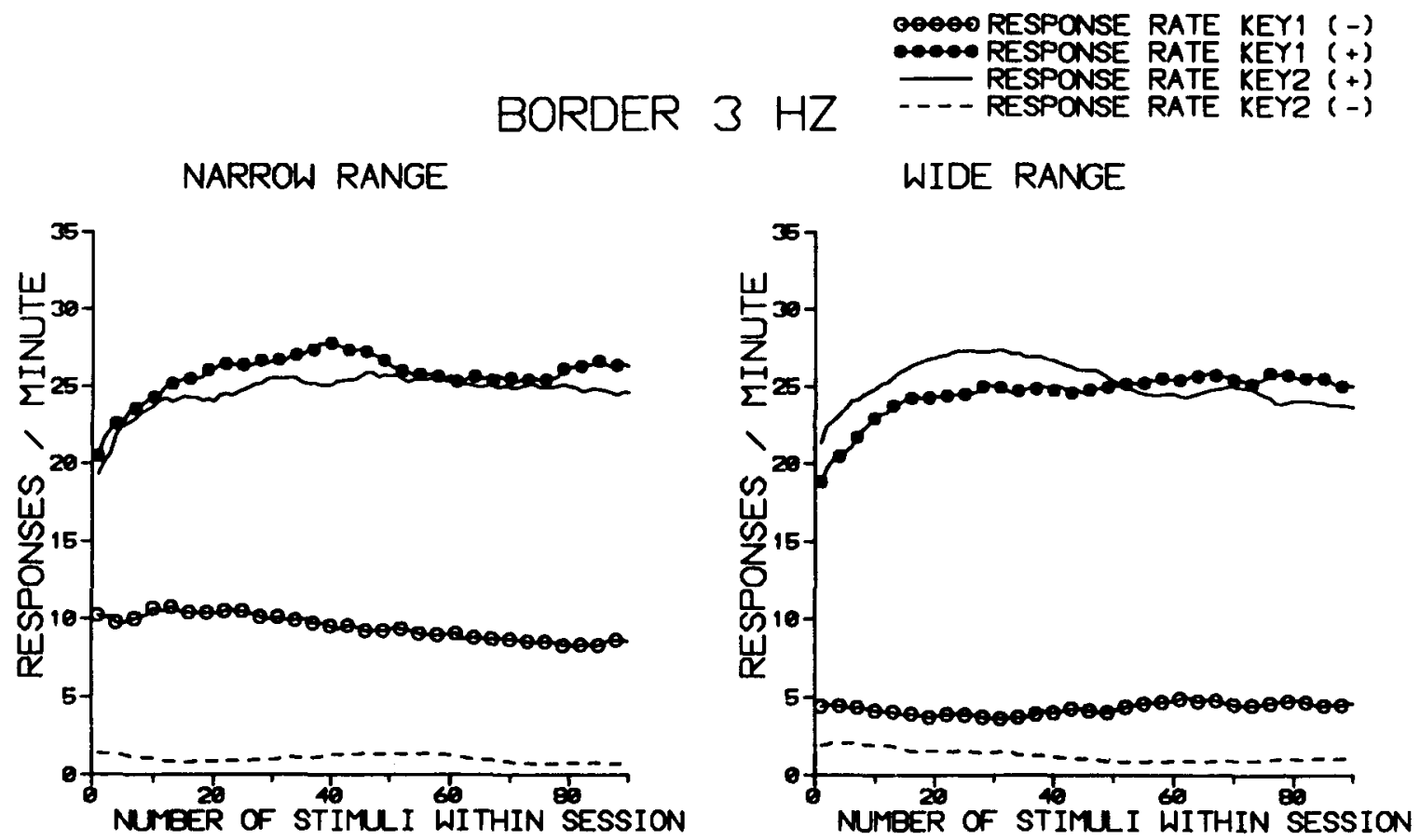

Figure 6. Running mean of response rate over 30 consecutive stimulus components, averaged over all subjects for the last seven sessions of training with a 3-Hz border in Experiment 1. Stimulus range conditions appear in the left panel (narrow) and right panel (wide).

Responses to the red color key during the two highest flicker-rate stimuli were reinforced, whereas responses to the green color key during these stimuli produced a blackout. A daily session included 98 trials and took approximately $30 \mathrm{~min}$ to complete. The stimulus values and training conditions were identical to those appearing in Figure 1, which were also used in Experiment 1. Training on each condition was provided for 14 consecutive daily sessions. The order of conditions was different for each bird.

\section{Results and Discussion}

Table 1 gives the results from Experiment 2 for individual birds and the means across all 4 birds. Results are taken from the last 7 sessions for each condition. Included in Table 1 are probabilities of hits (correct selection of Key 1 for Stimulus 2) and false alarms (incorrect selection of Key 1 for Stimulus 3), as well as indices of sensitivity $\left(A^{\prime}\right)$ and response bias $\left(B^{\prime \prime}\right)$ derived from a nonparametric approach to measurement based on the geometry of the receiver operating characteristic (ROC) space (e.g., Aaronson \& Watts, 1987; Grier, 1971; Hodos, 1970).

For the $1-\mathrm{Hz}$ border conditions, a paired-sample $t$ test (with two-tail criterion of .05) showed no significant change across range conditions for hits, false alarms, and the index $B^{\prime \prime}$. However, there was a significant decrease in $A^{\prime}$, from .757 in the narrow range condition to .675 in the wide range condition $[t(3)=4.533]$. Similarly, for the $3-\mathrm{Hz}$ border conditions, the only reliable change was a significant decrease in $A^{\prime}$, from .899 in the narrow range condition to .852 in the wide range condition $[t(3)=$ 4.724]. Thus, for both the easier and the more difficult discrimination conditions, perceptual sensitivity, indicated by $A^{\prime}$, declined as stimulus range was increased.

A reasonably direct comparison can be made between the results of Experiment 1 and Experiment 2. For this comparison, we treated the multiple-schedule components in Experiment 1 as though they were discrete trials. The first response made to either Key 1 or Key 2 during each stimulus presentation was used as the choice for that stimulus. We then computed hits and false alarms in the same way as the discrete trial choices for Experiment 2. Previous work has shown that the first response occurring in a multiple-schedule choice procedure is a good index of discrimination performance (Hinson \& Higa, 1989). In the present analyses, the results did not change substantially when hits and false alarms were calculated on the basis of the sum of the first 5 or first 50 responses during each stimulus component, instead of the first response.

Table 2 provides a summary of hits, false alarms, and $A^{\prime}$ and $B^{\prime \prime}$ statistics for the converted response rates from Experiment 1 . For the $1-\mathrm{Hz}$ border conditions, there were no significant changes across range conditions for hits or $B^{\prime \prime}$. But there was a significant decrease in $A^{\prime}$, from .765 in the narrow range condition to .690 in the wide range condition $[t(3)=3.475]$. Furthermore, there was a significant increase in false alarms, from .39 in the narrow range condition to .64 in the wide range condition $[t(3)=5.815]$. The same pattern appears for the $3-\mathrm{Hz}$ border conditions of Experiment 2. There was a significant decrease in $A^{\prime}$, from .929 in the narrow range condition to .850 in the wide range condition $[t(3)=12.935]$, and an increase in false 
Table 1

Hits, False Alarms (FAs), Sensitivity Index $A^{\prime}$, and Response Bias Index $B^{\prime \prime}$, for All Conditions in Experiment 2

\begin{tabular}{|c|c|c|c|c|}
\hline & Hits & FAs & $A^{\prime}$ & $B^{\prime \prime}$ \\
\hline \multicolumn{5}{|c|}{ 1-Hz Border } \\
\hline Narrow Range & $\begin{array}{l}.47 \\
.75 \\
.71 \\
.77 \\
.68\end{array}$ & $\begin{array}{l}.27 \\
.41 \\
.28 \\
.36 \\
.33\end{array}$ & $\begin{array}{l}.675 \\
.757 \\
.801 \\
.793 \\
.757\end{array}$ & $\begin{array}{r}.117 \\
-.127 \\
.010 \\
-.131 \\
-.033\end{array}$ \\
\hline Wide Range & $\begin{array}{l}.29 \\
.85 \\
.74 \\
.70 \\
.65\end{array}$ & $\begin{array}{l}.20 \\
.67 \\
.42 \\
.52 \\
.45\end{array}$ & $\begin{array}{l}.606 \\
.689 \\
.746 \\
.658 \\
.675\end{array}$ & $\begin{array}{r}.125 \\
-.269 \\
-.117 \\
-.086 \\
-.087\end{array}$ \\
\hline \multicolumn{5}{|c|}{ 3-Hz Border } \\
\hline Narrow Range & $\begin{array}{l}.73 \\
.93 \\
.81 \\
.92 \\
.85\end{array}$ & $\begin{array}{l}.22 \\
.20 \\
.19 \\
.09 \\
.18\end{array}$ & $\begin{array}{l}.838 \\
.924 \\
.883 \\
.954 \\
.899\end{array}$ & $\begin{array}{r}.069 \\
-.422 \\
.000 \\
-.053 \\
-.102\end{array}$ \\
\hline Wide Range & $\begin{array}{l}.56 \\
.90 \\
.78 \\
.87 \\
.78\end{array}$ & $\begin{array}{l}.22 \\
.28 \\
.26 \\
.15 \\
.23\end{array}$ & $\begin{array}{l}.761 \\
.888 \\
.842 \\
.919 \\
.852\end{array}$ & $\begin{array}{r}.179 \\
-.382 \\
-.057 \\
-.059 \\
-.079\end{array}$ \\
\hline
\end{tabular}

alarms, from .17 in the narrow range condition to .34 in the wide range condition $[t(3)=7.892]$.

In summary, the converted response rate data from Experiment 1 show the same decline in sensitivity, measured by $A^{\prime}$, as found in Experiment 2. There was a statistically significant change in false alarms with increased stimulus range, which was found only in Experiment 1. Furthermore, mean values of $B^{\prime \prime}$ were higher in all conditions of Experiment 1 when compared with those of Experiment 2, indicating greater response bias with the continuous response rate procedure. However, there were no statistically significant changes in $B^{\prime \prime}$ across range conditions in Experiment 1.

Figure 7 provides an analysis of local changes in responding from Experiment 2 based on a running mean of 20 trials, averaged across all 4 birds. The figure shows functions for hits and false alarms in all conditions of Experiment 2. Inspection of Figure 7 reveals very modest changes in hits and false alarms within sessions. There is no consistent patterning of hits and false alarms across subjects, within the limits of overall variability.

Figure 8 provides running means across 20 trials for the indices $A^{\prime}$ and $B^{\prime \prime}$, based on the data in Figure 7. For the $1-\mathrm{Hz}$ border conditions, both sets of functions showed little noteworthy change over the course of the session. The $B^{\prime \prime}$ index was more variable within sessions for the $3-\mathrm{Hz}$ border conditions, but this variability had no impact on the stability of $A^{\prime}$. In summary, Figure 8 shows no changes in local responding that are correlated with overall differences in performance produced by manipulation of stimulus range.

Some theorists have argued that, in psychophysical tasks, human observers track payoffs for different re- sponses on each trial and adjust response criteria accordingly (e.g., Treisman, 1984; Treisn an \& Williams, 1984). If pigeons use a similar tracking process, there should be multiple mean shifts in the placement of the response criterion during each session. One consequence of these continual shifts would be greater overall variability in the response criterion, which could easily be mistaken for a decline in sensitivity (see Macmillan \& Creelman, 1991). If the tracking process were most variable with wider stimulus ranges, a response-based, criterion-tracking mechanism could be responsible for what otherwise seems to be a decline in perceptual sensitivity when stimulus range is increased.

Figure 9 provides a plot of hits and false alarms, based on Stimuli 2 and 3, as a function of preceding stimulus. The left panel shows results from the $1-\mathrm{Hz}$ border conditions; the right panel shows results from the $3-\mathrm{Hz}$ border conditions. A tracking mechanism, like the one described above, should produce differences in hits or false alarms depending on the prior stimulus. For example, after a trial with Stimulus 1 or Stimulus 4 in a wide range condition, we might expect more false alarms, fewer hits, or both. However, as Figure 9 indicates, hits and false alarms did not change as a function of the stimulus on the preceding trial. We found global differences in hits and false alarms across conditions, but no important local differences by this analysis.

Another indication of a tracking mechanism would be increased variability in hits and false alarms as a function of the stimulus on the preceding trial. Table 3 provides the variance for each of the data points shown in Figure 9. An inspection of Table 3 reveals no consistent changes in the variability of hits and false alarms across

Table 2

Hits, False Alarms (FAs), Sensitivity Index $A^{\prime}$, and Response Bias Index B", Using Response Rate Conversions, for All Conditions in Experiment 1

\begin{tabular}{|c|c|c|c|c|}
\hline & Hits & FAs & $A^{\prime}$ & $B^{\prime \prime}$ \\
\hline \multicolumn{5}{|c|}{ 1-Hz Border } \\
\hline Narrow Range & $\begin{array}{l}.69 \\
.75 \\
.76 \\
.80 \\
.75\end{array}$ & $\begin{array}{l}.35 \\
.46 \\
.42 \\
.34 \\
.39\end{array}$ & $\begin{array}{l}.754 \\
.731 \\
.758 \\
.818 \\
.765\end{array}$ & $\begin{array}{l}-.031 \\
-.140 \\
-.143 \\
-.168 \\
-.121\end{array}$ \\
\hline Wide Range & $\begin{array}{l}.89 \\
.86 \\
.75 \\
.81 \\
.83\end{array}$ & $\begin{array}{l}.72 \\
.66 \\
.61 \\
.56 \\
.64\end{array}$ & $\begin{array}{l}.700 \\
.705 \\
.636 \\
.719 \\
.690\end{array}$ & $\begin{array}{l}-.346 \\
-.302 \\
-.119 \\
-.231 \\
-.250\end{array}$ \\
\hline \multicolumn{5}{|c|}{ 3-Hz Border } \\
\hline Narrow Range & $\begin{array}{l}.89 \\
.93 \\
.91 \\
.92 \\
.91\end{array}$ & $\begin{array}{l}.12 \\
.21 \\
.08 \\
.25 \\
.17\end{array}$ & $\begin{array}{l}.935 \\
.921 \\
.954 \\
.905 \\
.929\end{array}$ & $\begin{array}{r}-.038 \\
-.436 \\
.053 \\
-.436 \\
-.214\end{array}$ \\
\hline Wide Range & $\begin{array}{l}.80 \\
.89 \\
.84 \\
.91 \\
.86\end{array}$ & $\begin{array}{l}.28 \\
.41 \\
.20 \\
.47 \\
.34\end{array}$ & $\begin{array}{l}.843 \\
.838 \\
.891 \\
.828 \\
.850\end{array}$ & $\begin{array}{l}-.115 \\
-.424 \\
-.087 \\
-.505 \\
-.283\end{array}$ \\
\hline
\end{tabular}




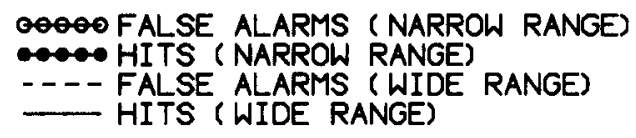

BORDER $1 \mathrm{HZ}$

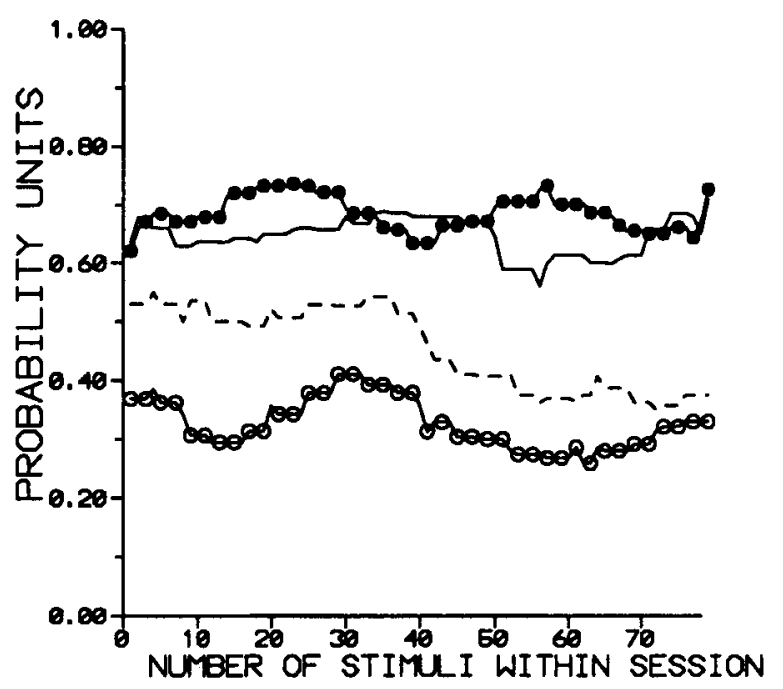

BORDER $3 \mathrm{HZ}$

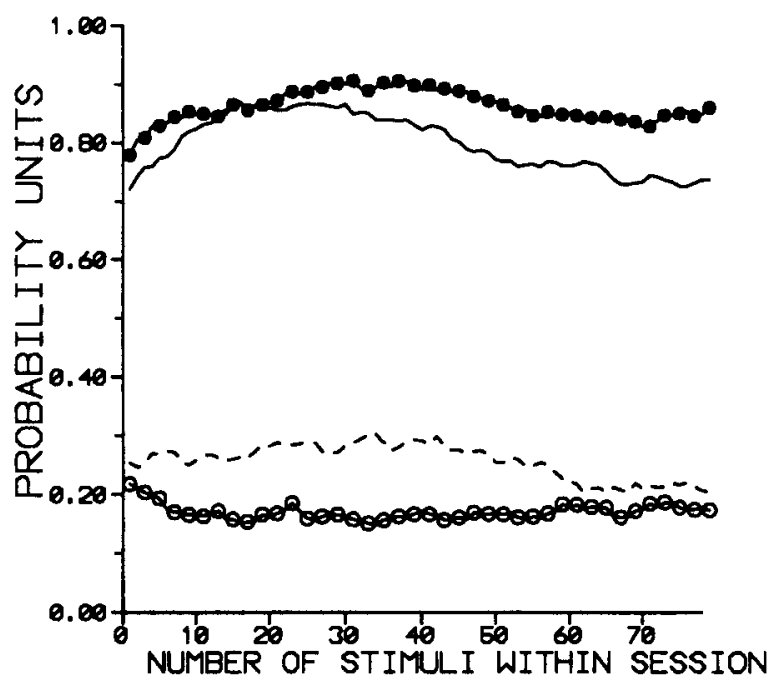

Figure 7. Running mean of 20 consecutive trials for hits and false alarms, averaged across all subjects over the last seven sessions, for narrow and wide stimulus range conditions of Experiment 2 . Training with the two different $S-/ S+$ borders appears in the left panel (1-Hz border) and right panel (3-Hz border).

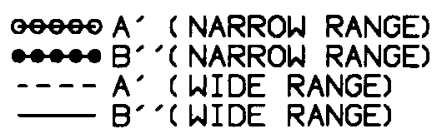

BORDER $\uparrow \mathrm{HZ}$

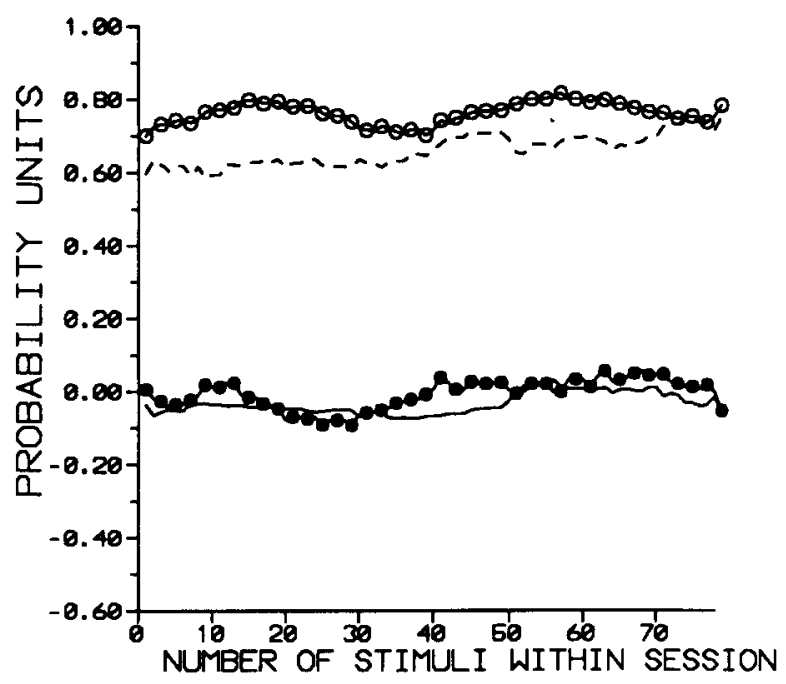

BORDER $3 \mathrm{HZ}$

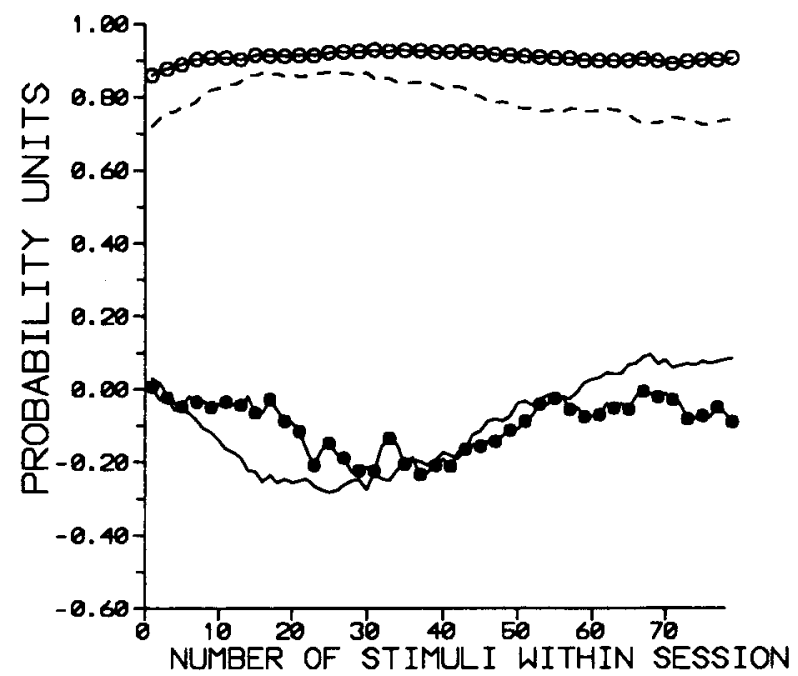

Figure 8. Running mean of 20 consecutive trials for sensitivity index $A^{\prime}$ and response bias index $B^{\prime \prime}$, averaged across all subjects over the last seven sessions, for narrow and wide stimulus range conditions of Experiment 2 . Training with the two different $S-/ S+$ borders appears in the left panel (1-Hz border) and right panel (3-Hz border). 


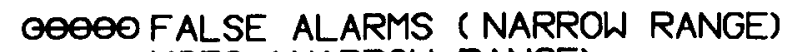 \\ ๑०० HITS (NARROW RANGE) \\ TOUOE FALSE ALARMS (WIDE RANGE) \\ HITS (WIDE RANGE)}

BORDER $1 \mathrm{HZ}$

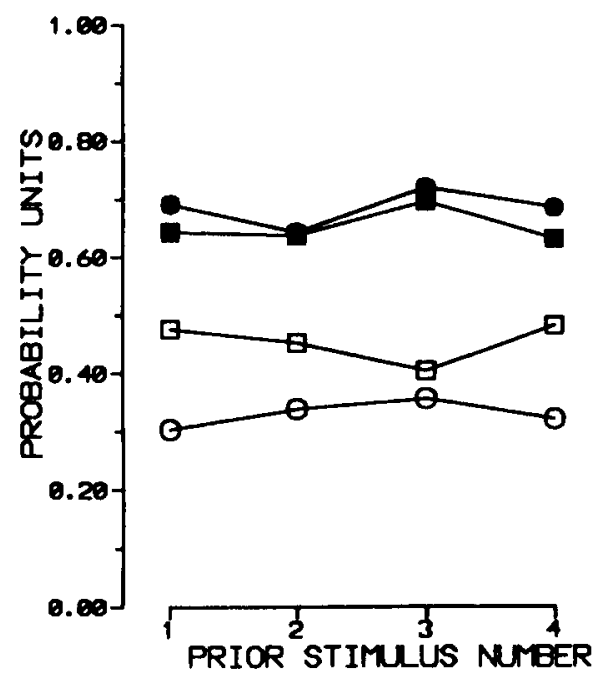

BORDER $3 \mathrm{HZ}$

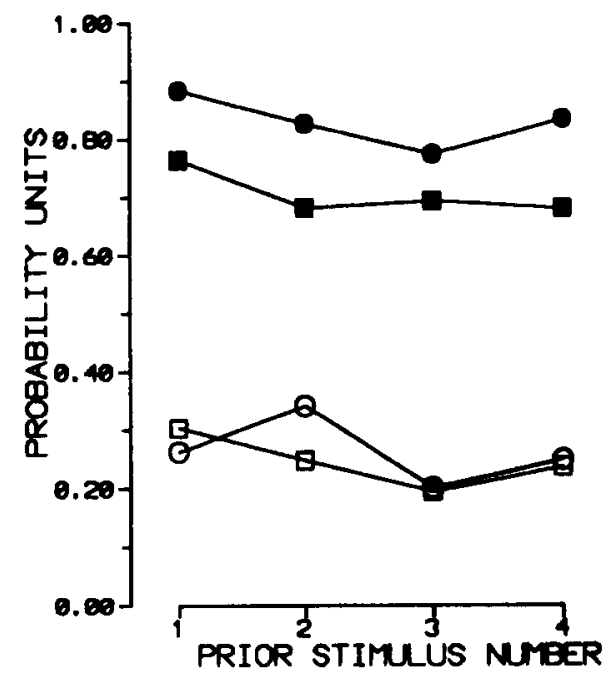

Figure 9. Plots of hits and false alarms as a function of the stimulus on the preceding trial, averaged across all subjects over the last seven sessions of each condition in Experiment 2 . The left panel is for results from the narrow border conditions; the right panel is for results from the wide border condition.

conditions or as function of preceding stimulus. Given the absence of local mean shifts in hits and false alarms, and the absence of changes in local variability, we conclude that there is no evidence for a trial-by-trial criterion tracking mechanism in this experiment.

Our results can be contrasted with findings reported by Purks, Callahan, Braida, and Durlach (1980) using human observers and absolute identification of auditory amplitudes. Purks et al. found that sensitivity did not improve when the preceding stimulus was similar to the current stimulus, a result similar to ours. However, they did find that response variance was smallest when the prior and current stimuli were similar. This effect on response variance was attributable to sequential effects in response bias. We found no effect on response variance as a function of preceding stimulus.

\section{EXPERIMENT 3}

The major finding from Experiment 2 was a decrease in perceptual sensitivity, indicated by $A^{\prime}$, with increases in stimulus range. We were unable to find any consistent changes in response factors, such as response bias, that contributed to range effects in Experiment 2. Removing response rate from the discrimination contingency seemed to eliminate response bias that appeared in Experiment 1.

Nonetheless, changes in response factors may contribute to range effects in more subtle ways than we have so far considered. For example, response criteria can change in two ways, either in terms of the mean location or in terms of the variability of location. Although we found no evidence of changes in the variability of the response criterion in Experiment 2, it is still possible that mean changes were occurring that were obscured by our procedure.

If the mean location of the response criterion changes with stimulus range, the symmetrical spread of stimuli in our wide range condition might interfere with measurement of the effect. For example, increasing stimulus range on the high end of the stimulus continuum might cause a mean criterion shift toward the high end, an effect known

Table 3

Variance in Hits and False Alarms (FAs) for Border Stimuli as a Function of the Stimulus on the Preceding Trial for Each Condition of Experiment 2

\begin{tabular}{|c|c|c|c|c|}
\hline \multirow[b]{2}{*}{ Prior Stimulus } & \multicolumn{2}{|c|}{ Narrow Range } & \multicolumn{2}{|c|}{ Wide Range } \\
\hline & Hits & FAs & Hits & FAs \\
\hline \multicolumn{5}{|c|}{ 1-Hz Border } \\
\hline 1 & .055 & .039 & .069 & .065 \\
\hline 2 & .057 & .065 & .093 & .080 \\
\hline 3 & .049 & .043 & .068 & .085 \\
\hline 4 & .040 & .043 & .095 & .034 \\
\hline \multicolumn{5}{|c|}{ 3-Hz Border } \\
\hline 1 & .021 & .060 & .052 & .076 \\
\hline 2 & .060 & .079 & .079 & .039 \\
\hline 3 & .076 & .046 & .061 & .040 \\
\hline 4 & .014 & .047 & .062 & .032 \\
\hline
\end{tabular}


as assimilation (e.g., Lockhead \& King, 1983; Warren, 1985). Similarly, increasing stimulus range on the low end of the continuum might shift the mean criterion to the low end. Increasing stimulus range on both ends of the stimulus continuum could lead to an averaging out of any mean criterion shifts. Experiment 3 was designed to clarify the impact of mean shifts in response criteria by extending stimulus range asymmetrically. Either the lowest or the highest flicker rate, but not both, was increased in different conditions.

\section{Method}

Subjects. The subjects were those who served in Experiment 2. During a period of over 4 months between Experiments 2 and 3, the subjects were idle. Maintenance conditions were identical to those in Experiment 2.

Apparatus. The apparatus was that employed in Experiment 2.

Procedure. The general procedure for Experiment 3 was the same as that for Experiment 2, except that 192 trials were included in each session. The sessions took approximately $55 \mathrm{~min}$ to complete. Training stimuli and conditions for Experiment 3 are illustrated in Figure 10. Included are a narrow range condition, identical to the narrow condition with $1-\mathrm{Hz}$ border in Experiments $\mathrm{I}$ and 2 , and two asymmetrical range manipulations, labeled low spread and high spread. Training on each condition was provided for 14 consecutive daily sessions. Order of conditions was randomly assigned for each bird.

\section{Results and Discussion}

Table 4 provides a summary of the mean values of hits, false alarms, $A^{\prime}$, and $B^{\prime \prime}$, averaged across all birds, over the last 7 sessions of each condition in Experiment 2. The mean values of both hits and false alarms increased from the narrow to low spread conditions, whereas hits and false alarms decreased from the narrow to high spread conditions. The index $B^{\prime \prime}$ indicates that there was some asymmetry in the way the-response criterion was changing across conditions. Ideally, $B^{\prime \prime}$ should be zero in the narrow condition. Nonetheless, the low spread made $B^{\prime \prime}$ more negative, and the high spread made $B^{\prime \prime}$ more positive, compared with the narrow condition. This is the expected pattern of results when the response criterion shifts in the direction of the spread stimulus (see Lockhead \& King, 1983). Therefore, increasing stimulus range in the direction of Stimulus 1 also increases the likelihood

\section{RESPONSE 1 RESPONSE 2}

[BORDER $1 \mathrm{HZ}]$

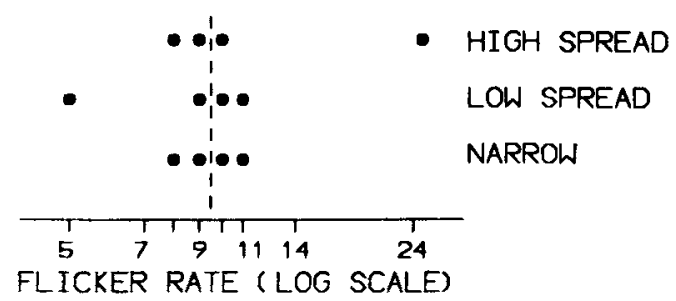

Figure 10. Schematic representation of training stimuli for Experiment 3 .
Table 4

Hits, False Alarms (FAs), Sensitivity Index $A^{\prime}$, and Response Bias Index $B^{\prime \prime}$ for All Conditions in Experiment 3

\begin{tabular}{ccccc}
\hline & Hits & FAs & $A^{\prime}$ & $B^{\prime \prime}$ \\
\hline Low Spread & .84 & .74 & .626 & -.177 \\
& .85 & .46 & .795 & -.322 \\
& .87 & .79 & .618 & -.189 \\
Mean & .74 & .40 & .757 & -.110 \\
Narrow Range & .83 & .60 & .699 & -.200 \\
& .62 & .39 & .687 & -.004 \\
& .80 & .29 & .839 & -.125 \\
Mean & .66 & .49 & .648 & -.054 \\
High Spread & .83 & .26 & .864 & -.154 \\
& .73 & .36 & .760 & -.073 \\
& .31 & .26 & .557 & .050 \\
Mean & .70 & .29 & .791 & .009 \\
& .43 & .41 & .520 & .006 \\
& .62 & .25 & .773 & .114 \\
& .52 & .30 & .660 & .045 \\
\hline
\end{tabular}

that the subject will make the response associated with Stimulus 1 to any given stimulus. As stimulus range is increased in the direction of Stimulus 4 , the subject is more likely to make the response associated with Stimulus 4 to any stimulus.

Table 4 also indicates that the sensitivity index, $A^{\prime}$, decreased in low and high spread conditions, compared with the narrow condition. Thus, along with the observed change in response bias that produced a mean criterion shift, sensitivity was lower when stimulus range was increased. A within-subjects, repeated measures analysis of variance confirmed that changes in $B^{\prime \prime}[F(2,6)=20.339]$ and changes in $A^{\prime}[F(2,6)=10.943]$ were both statistically significant across the three stimulus range conditions.

Figure 11 displays local changes in responding during each condition of Experiment 3 , averaged across subjects. The running mean of 20 consecutive trials shows differences in hits and false alarms reflected in the overall measures of performance. As in Experiments 1 and 2, local changes within sessions were small and unsystematic. Similar results appear in Figure 12, which provides a running mean of $A^{\prime}$ and $B^{\prime \prime}$ averaged across birds for each condition. As in Experiment 2, the sensitivity index was quite stable within sessions for each condition. Response bias was most variable in the low stimulus spread condition. Again, there were no systematic changes in $B^{\prime \prime}$ within sessions that help to explain the overall effect of stimulus range.

\section{GENERAL DISCUSSION}

The results of the present experiments confirm and extend previous research demonstrating the existence of range effects in instrumental conditioning (Chase, 1983; Hinson \& Lockhead, 1986; Tennison \& Hinson, 1993). With all of the procedures used here, increased stimulus range produced a decrease in discrimination performance between constant stimuli. This decrease appeared in different tasks involving relative choice with either contin- 

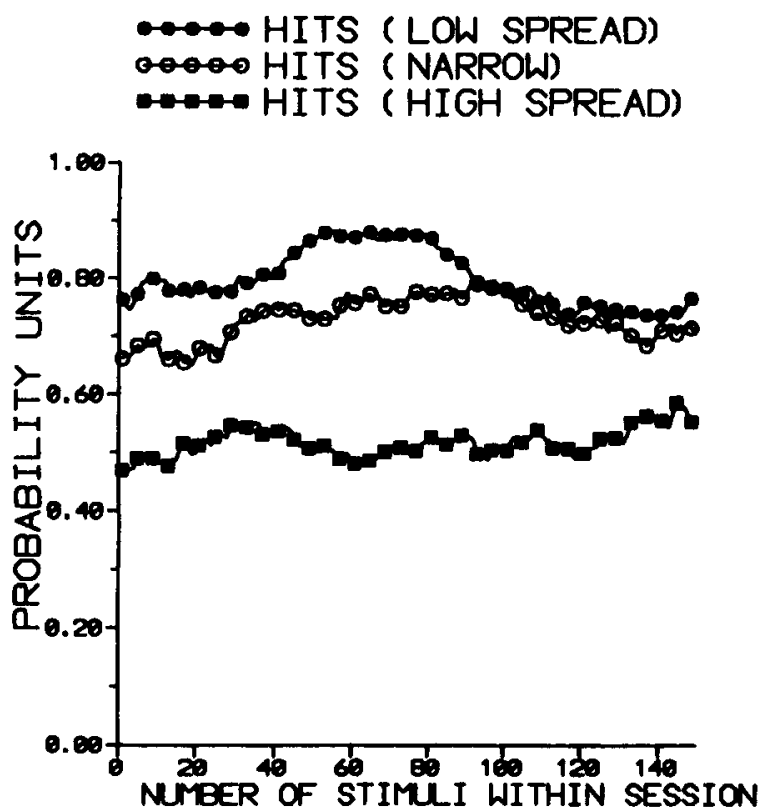
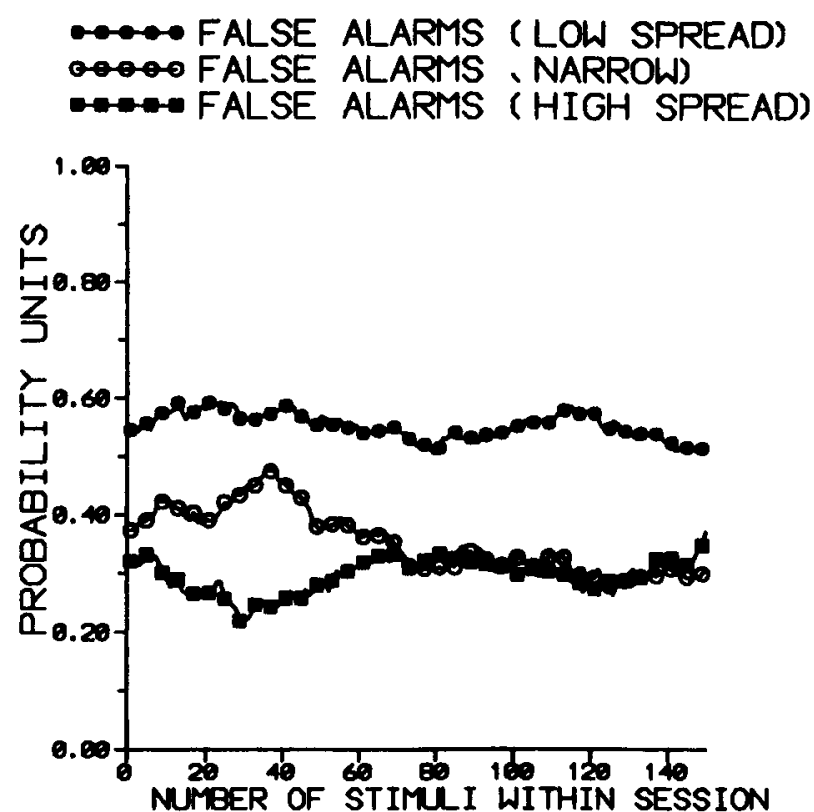

Figure 11. Running mean of 20 consecutive trials for hits and false alarms, averaged across all subjects over the last seven sessions of Experiment 3. The left panel provides curves for hits during each stimulus range condition; the right panel provides curves for false alarms during each stimulus range condition.
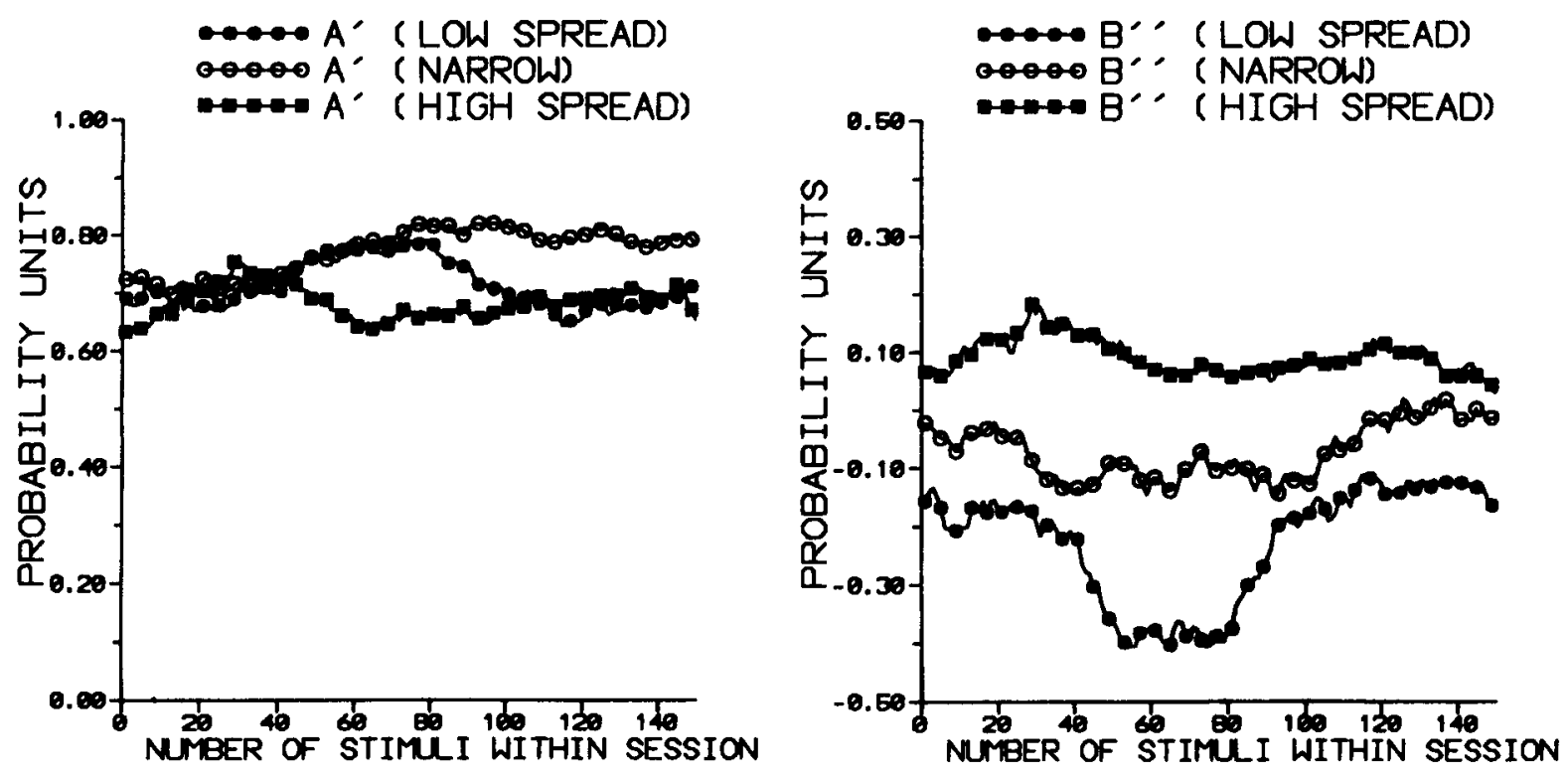

Figure 12. Running mean of 20 consecutive trials for sensitivity index $A^{\prime}$ and response bias index $B^{\prime \prime}$, averaged across all subjects over the last seven sessions of Experiment 3. The left panel provides curves for $A^{\prime}$ for each stimulus range condition; the right panel provides curves for $B^{\prime \prime}$ for each stimulus range condition.

uous response rate or discrete response procedures. Thus, range effects in instrumental conditioning do not rely on a special kind of reinforcement contingency or type of dependent measure of behavior.

One of our primary concerns is whether range effects in instrumental conditioning reflect changes in the types of factors suggested by models of human psychophysi- cal judgment (e.g., Durlach \& Braida, 1969; Gravetter \& Lockhead, 1973; Luce \& Green, 1978). Prior work has suggested that range effects in the present settings might be due to changes in response factors, such as response bias (Hinson \& Lockhead, 1986; Tennison \& Hinson, 1993). This suggestion is consistent with one of the most basic tenets of the detection model: Discriminability be- 
tween stimuli should be attributable to the difference in distributions of sensory effect produced by those stimuli (e.g., Green \& Swets, 1966). Changes in the distribution or frequency of training stimuli, or changes in payoffs, should only affect the degree of bias, or preference, for response options. If range effects were solely attributable to response bias, then stimulus range could be considered a nuisance variable in studies of discrimination learning. As a nuisance variable, it would require control in experimental design to avoid confounds, but stimulus range would not reveal anything fundamentally important about mechanisms of discrimination learning.

Contrary to this argument, all of our results gave indications of changes in perceptual sensitivity as stimulus range was manipulated. Decreases in relative response rate indicative of a decline in sensitivity were found in Experiment 1. In Experiments 2 and 3, as well as in converted data from Experiment 1, the measure $A^{\prime}$ revealed declines in sensitivity as stimulus range was increased.

We examined the possibility of a response-criteriontracking mechanism that could potentially explain range effects in terms of response processes alone (e.g., Treisman, 1984; Treisman \& Williams, 1984). If this tracking process were sensitive to stimulus range, we would expect to see multiple mean shifts in the placement of the response criterion locally in time, which would increase the overall variability of the criterion. As noted earlier, increased criterial variability could easily be misinterpreted as a decline in sensitivity (see Macmillan \& Creelman, 1991).

Again, we found no substantial evidence of a responsecriterion-tracking mechanism. Plots of relative response rates within sessions in Experiment 1 showed low variability over time in both wide and narrow range conditions. Similarly, hits and false alarms, as well as measures of bias and sensitivity, for Experiments 2 and 3 showed no more variability in wide range conditions than in narrow range conditions. Examination of hits and false alarms as a function of the stimulus on the preceding trial gave no positive evidence for the operation of a local tracking mechanism. In summary, we found little evidence of important changes in performance that occur locally within sessions, even though, on the basis of prior work, we expected we would see such changes (e.g., McSweeney et al., 1996).

There is one obvious criticism of our argument that range effects reflect both changes in perceptual sensitivity and changes in response bias. As quantitative measures of sensitivity and bias, we used statistics derived from the geometry of the ROC space (Grier, 1971; Hodos, 1970). Recent analysis has shown that these geometric measures are not distribution free but instead imply underlying logistic distributions for most levels of discrimination accuracy (see Macmillan \& Creelman, 1996). On the basis of this criticism, one could argue that we cannot be absolutely confident that we have properly assessed the contribution of response bias or perceptual sensitivity to range effects using these measures.
It is also possible to make an even more general criticism of any quantitative measure applied to the present results. Every measure of sensitivity makes assumptions about the form of variability underlying distributions of sensory effect produced by stimuli. In the present experiments with limited numbers of data points, we cannot confirm a specific assumption about the form of underlying sensory variability. Furthermore, accurate measures of sensitivity rely on either a fixed response criterion or a criterion with known variability. Although we believe that response criteria are being changed by our stimulus range manipulations, we cannot specify exactly how the criteria are changing. As a result, any measure of sensitivity may misrepresent actual discriminability when range is manipulated.

Despite these criticisms, we believe that the use of geometric measures was justified in the present experiments. Because we had only a limited number of data points in each condition, any point estimate of sensitivity would have limited generality. Nevertheless, the values of $A^{\prime}$ and $B^{\prime \prime}$ obtained in Experiments 2 and 3 were quite stable within sessions, while still producing statistically reliable differences across experimental conditions. At present, we have no reason to believe that estimates of $A^{\prime}$ and $B^{\prime \prime}$ are misrepresenting our results.

On the basis of the present findings, we must recognize that range effects in instrumental conditioning are not solely due to response factors but are instead due to a combination of sensory factors and response factors, as earlier suggested by workers in human psychophysics (e.g., Luce \& Krumhansl, 1988; Nosofsky, 1983). Any adequate theoretical model of range effects should account for the impact of both of these factors.

At present, there is only one well-developed theoretical model of range effects with animals in conditioning settings - the one proposed by Chase (1983). This model is based on a conception of a limited-capacity memory. According to the model, on each trial, memory records are stored that retain information about the stimulus presented, the response made, and whether reinforcement was obtained. When capacity limits are reached, each new record replaces an older record, so that records are continually overwritten during training. Choices of response on each trial are presumed to be based on a limited sample taken from the available records. The model, therefore, proposes three possible sources of error in discrimination: (1) error due to overlap among sensory representations, (2) error due to confusion among response choices, and (3) error resulting from limitations on sample sizes taken from memory.

Chase's model provides a reasonable account for the kinds of classic range effects discussed by Miller (1956). As one example, two stimuli may be easily discriminated when they are part of a small set of stimuli being judged during an experiment. But the same two stimuli may be poorly discriminated when they are part of a much larger set of stimuli. Chase's model suggests that increasing the number of stimuli reduces discrimination accuracy be- 
cause each stimulus in the larger stimulus set is represented in memory by relatively fewer records. Thus, increasing stimulus range by adding stimuli to the discrimination task leads to a poorer internal representation of each stimulus, and, therefore, it leads to less accurate discrimination.

It is not clear what prediction the model would make for the range manipulation used in the present experiments. We can, however, eliminate one possible source of error implied by the model. In all of the experiments reported here, total number of training stimuli was constant in all conditions. As a result, the relative number of available memory records for each stimulus should not have changed across conditions. Hence, the capacity limitations in memory suggested by Chase's model cannot explain the range effects reported in the present experiments.

The remaining possible sources of error concern either the overlap of sensory representations or the degree of confusion between response alternatives. Stimuli at the border of the two response classes, Stimuli 2 and 3, were constant for each comparison of narrow and wide stimulus ranges. So the overlap between the internal representations of these stimuli should also remain constant. Increasing stimulus range by changing the physical value of Stimulus 1 or 4 , the stimuli at the ends of the continuum, should have no effect on the representation of Stimulus 2 or 3. Finally, on the basis of the model's assumptions, there is no obvious reason why response alternatives should be more readily confused in the wide range conditions than in the narrow range conditions.

Additional assumptions appear to be necessary for Chase's model to explain the present findings. A missing theoretical element may be an attentional mechanism. In another setting, we have argued that an attentional mechanism may be responsible for important features of visual discrimination and generalization by pigeons (see Hinson \& Tennison, 1997). In our view, attention behaves like a gradient extending over the pertinent region of an internal representation of the stimuli being discriminated during the training task. Because a wider range of stimuli requires that limited attentional resources be more widely distributed, discrimination performance necessarily suffers. This attentional mechanism is somewhat similar to the attention band described earlier (e.g., Luce \& Nosofsky, 1984), although we have not made the same assumptions about the dynamics of attention over trials. In general, a decline in the allocation of attentional resources could easily account for a reduction in perceptual sensitivity when stimulus range is increased. Future work should determine whether there is sufficient evidence for the role of an attentional mechanism in the production of range effects and whether this mechanism can account for changes in both sensory factors and response factors.

\section{REFERENCES}

Aaronson, D., \& WatTs, B. (1987). Extensions of Grier's computational formulas for $A^{\prime}$ and $B^{\prime \prime}$ to below chance performance. Psychological Bulletin, 102, 439-442.

Algom, D., \& MARKS, L. E. (1990) Range and regression, loudness scales, and loudness processing: Toward a context-bound psychophysics. Journal of Experimental Psych logy. Human Perception \& Performance, 16, 706-727.

BALSAM, P. D. (1988). Selection, representation, and equivalence of controlling stimuli. In R. C. Atkinson, R. J. Herrnstein, G. Lindzey, \& R. D. Luce (Eds.), Stevens' Handbook of experimental psychology (Vol. 2, pp. 111-166). New York: Wiley.

BLOUGH, D. S. (1965). Definition and measurement in generalization research. In D. Mostofsky (Ed.), Stimulus generalization (pp. 30-37). Stanford: Stanford University Press.

BLOUGH, D. S. (1967). Stimulus generalization as signal detection in pigeons. Science, 158, 940-941.

BLOUGH, D. S. (1975). Steady state data and a quantitative model of operant generalization and discrimination. Journal of Experimental Psychology: Animal Behavior Processes, 104, 3-21.

BLough, D. S. (1983). Alternative accounts of dimensional stimulus control. In M. Commons, R. Herrnstein, \& A. Wagner (Eds.), Quantitative analyses of behavior (Vol. 4, pp. 59-72). Cambridge, MA: Ballinger.

Blough, P. M. (1980). Behavioral and dimensional contrast in rats. Journal of the Experimental Analysis of Behavior, 33, 345-357.

Boneau, C. A., \& COLE, J. L. (1967). Decision theory, the pigeon, and the psychophysical function. Psychological Review, 74, 123-135

BraidA, L. D., \& DURLACH, N. I. (1972). Intensity perception: II. Resolution in one interval paradigms. Journal of the Acoustical Society of America, 51, 483-502.

Chase, S. (1983). Pigeons and the magical number seven. In M. Commons, R. Herrnstein, \& A. Wagner (Eds.), Quantitative analyses of behavior (Vol. 4, pp. 37-57). Cambridge, MA: Ballinger.

Durlach, N. I., \& Braida, L. D. (1969). Intensity perception: I. Preliminary theory of intensity resolution. Journal of the Acoustical Society of America, 46, 372-383.

FREDERIKSEN, J. R. (1975). Two models for psychophysical judgment. Scale invanance with changes in stimulus range. Perception \& Psychophysics, 17, 147-157.

GravetTer, F., \& LOCKHEAD, G. R. (1973). Criterial range as a frame of reference for stimulus judgment. Psychological Review, 80, 203-216.

Green, D. M., \& Swets, J. A. (1966). Signal detection theory and psychophysics. New York: Wiley.

GRIER, J. B. (1971). Nonparametric indexes for sensitivity and bias: Computing formulas. Psychological Bulletin, 75, 424-429.

HaNSON, H. M. (1959). Effects of discrumination training on stimulus generalization. Journal of Experimental Psychology, 58, 321-334.

Heinemann, E. G., Avin, E., Sullivan, M. A., \& Chase, S. (1969). Analysis of stımulus generalization with a psychophysical method. Journal of Experimental Psychology, 80, 215-224.

HeinemanN, E. [G.], \& Chase, S. (1975). Stimulus generalization. In W. K. Estes (Ed.), Handbook of learning and cognitive processes (Vol 2, pp. 305-349). Hillsdale, NJ: Erlbaum.

Hinson, J. M., \& HiGA, J. J. (1989). Discrete and continuous measures of dimensional stimulus control. Journal of the Experimental Analysis of Behavior, 51, 199-214.

Hinson, J. M., \& LockHEAD, G. R. (1986). Range effects in successive discrimination. Journal of Experimental Psychology: Animal Behavior Processes, 12, 270-276.

Hinson, J. M., \& Tennison, L. R. (1997). An attentional model of dimensional contrast. Journal of Experimental Psychology' Animal Behavior Processes, 23, 295-311.

HoDos, W. (1970). A nonparametric index of response bias for use in detection and recognition experiments. Psychological Bulletin, 75, 351-354.

LockheAd, G. R., \& KING, M L. (1983). A memory model of sequential effects in scaling tasks. Journal of Experimental Psychology: Human Perception \& Performance, 9, 461-473.

LUCE, R. D., \& GREEN, D. M. (1978). Two tests of a neural attention hypothesis for auditory psychophysics. Perception \& Psychophysics, 23, 363-371.

LuCE, R. D., Green, D. M., \& Weber, D. L. (1976). Attention bands in absolute identification. Perception \& Psychophysics, 20, 49-54.

LuCE, R. D , \& Krumhansi, C. L. (1988). Measurement, scaling, and psychophysics. In R. C. Atkinson, R. J. Herrnstein, G. Lindzey, \& 
R. D. Luce (Eds.), Stevens' Handbook of experimental psychology (Vol. 1, pp. 3-74). New York: Wiley.

LUCE, R. D., \& NoSOFSKY, R. M. (1984). Attention, stimulus range, and 1dentification of loudness. In S. Kornblum \& J. Requin (Eds.), Preparatory states and processes (pp. 3-25). Hillsdale, NJ: Erlbaum.

Macmillan, N. A., \& Creelman, C. D. (1991). Detection theory: $A$ user's guide. New York: Cambridge University Press.

Macmillan, N. A., \& Creelman, C. D. (1996). Triangles in ROC space. History and theory of "nonparametric" measures of sensitivity and response bias. Psychonomic Bulletin \& Review, 3, 164-170.

MCNicol, D. (1972). A primer of signal detection theory Sydney: Allen \& Unwin.

MCSWEENEY, F. K., \& Hinson, J. M. (1992). Patterns of responding within experimental sessions. Journal of the Experimental Analysis of Behavior, 58, 19-36.

MCSweEney, F. K., Hinson, J. M., \& Cannon, C. B. (1996). Sensitization-habituation occurs in operant conditioning procedures. Psychological Bulletin, 120, 256-271.

Miller, G. A. (1956). The magical number seven, plus or minus two: Some limits on our capacity for processing information. Psychological Review, 63, 81-97.

NosofsKy, R. M. (1983). Information integration and the identification of stımulus noise and criterial noise in absolute judgment. Journal of Experimental Psychology. Human Perception \& Performance, 9, 299-309.

Parducci, A. (1974). Contextual effects: A range-frequency analysis. In E. C. Carterette \& M. P Friedman (Eds.), Handbook of perception (Vol. 2, pp. 127-141). New York: Academic Press.

Parker, S., \& Schneider, B. (1994). The stımulus range effect: Evi- dence for top-down control of sensory intensity in audition. Perception \& Psychophysics, 56, 1-11.

POLLACK, I. (1952). The information of elementary auditory displays. Journal of the Acoustical Society of America, 24, 745-749.

Purks, S. R., Callahan, D. J., Braida, L. D., \& Durlach, N. I. (1980). Intensity perception: X. Effects of preceding stimulus on identification performance. Journal of the Acoustical Society of America, 67, 634-637.

SPENCE, K. W. (1937). The differential response in animals to stimuli varying within a single dimension. Psychological Review, 44, 430-444.

Tennison, L. R., \& Hinson, J. M. (1993). Range effects in transient and maintained generalization gradients. Behavioral Processes, 29, 201-216.

Treisman, M. (1984). A theory of criterion setting: An alternative to the attention band and response ratio hypotheses in magnitude estimation and cross-modality matching. Journal of Experimental Psychology: General, 113, 443-463.

Treisman, M., \& Williams, T. C. (1984). A theory of criterion setting with an application to sequential dependencies. Psychological Review, 91, 68-111.

WARREN, R. M. (1985). Criterion shift rule and perceptual homeostasis. Psychological Review, 92, 574-584.

WiLliams, B. A. (1983). Another look at contrast in multiple schedules. Journal of the Experimental Analysis of Behavior, 39, 345-384.

(Manuscript received July 11, 1997; revision accepted for publication November 6,1997 .) 